\title{
Retraction Note to: OECD BEPS: Reconciling Global Trade, Taxation Principles and the Digital Economy
}

\section{Hosuk Lee-Makiyama and Bert Verschelde}

Retraction Note:

Chapter "OECD BEPS: Reconciling Global Trade, Taxation Principles and the Digital Economy" in: Francesco Boccia and Robert Leonardi, The Challenge of the Digital Economy, DOI 10.1007/978-3-319-43690-6_4 The chapter published in the book 'The Challenge of the Digital Economy', pages 55-69, DOI 10.1007/978-3-319-43690-6_4 has been retracted because Palgrave does not have the publication rights.

The online version for this chapter can be found at 10.1007/978-3-319-43690-6_4

(C) The Author(s) 2017

F. Boccia, R. Leonardi (eds.), The Challenge of the Digital Economy, 10.1007/978-3-319-43690-6_9 